\title{
A Three Dimensional Web Quality Model ${ }^{1}$
}

\author{
Julián Ruiz, Coral Calero, and Mario Piattini \\ Computer Science Department. University of Castilla-La Mancha \\ Paseo de la Universidad, 4 \\ 13071, Ciudad Real (Spain) \\ \{Julian.Ruiz, Coral.Calero, Mario.Piattini\}@uclm.es
}

\begin{abstract}
We propose a model, whose primary objective is web quality assessment. Furthermore, the model can be used for the classification of web metrics, and the classification of web research works.
\end{abstract}

\section{The Model}

The model is based on the work developed by [4]. Figure 1 shows a graphic representation of our model. In this figure, we can observe each model dimension: features, quality characteristics, and life cycle processes. Each dimension must be considered as a hierarchical structure, composed by other more basic elements.

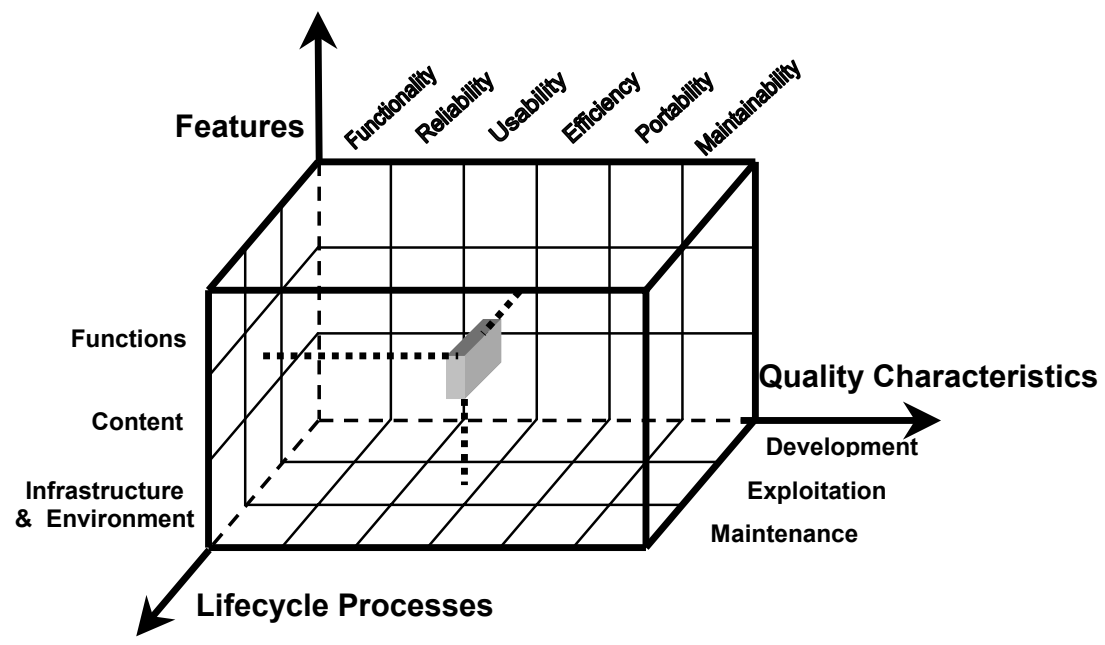

Fig. 1. Graphic representation of the model.

1 This research is part of the TAMANSI project (PCB-02-001) supported by the Consejería de Ciencia y Tecnología of Junta de Comunidades de Castilla-La Mancha (Spain). 
For the quality characteristic dimension, we use the standard ISO 9126 [1], extended with characteristics of the Quint2 model [3], and for the life cycle processes dimension, we use the standard ISO 12207-1 [2].

\section{Applications of the Model}

The model can be used for:

1. Classifying existing metrics. In this way, we will be able to know, in which cell we have metrics. Once we know this information, we will be able to use the metrics for the correct purpose. As a result of the classification of the existing metrics, we will know which cell has been disregarded, and it will be needed to propose new metrics.

2. Research works characterization. To determine the reach and the scope that have the works developed in a subject as multidimensional as the one of the web quality.

3. Web quality assessment. The quality of a web site will be represented by a set of indicators that will be obtained for each region of the cube. These indicators will be calculated in function of more elemental metrics, as lineal dependencies or more elaborated functions. In this way, the model provides a flexible framework to the evaluation of a web site, which can be used by system stakeholders from different perspectives, making possible to concentrate in certain aspects, or to detach from them (when we go from subcharacteristics to characteristics). Each of these perspectives or scenarios has its own representation in the model, like a region of the cube.

This is a preliminary version of the model. Therefore, it should be taken as an idea that must be evolutionary. For instance, we keep on working in the revision of quality subcharacteristics for a more appropriate adaptation to the web. And likewise, we consider to include the main processes of acquisition and provision in the life cycle processes dimension.

\section{References}

1. ISO/IEC (1995) ISO/IEC 12207. Information Technology. Software Life Cycle Processes.

2. ISO/IEC (1999) ISO/IEC 9126. Software Product Evaluation-Quality Characteristics and Guidelines for their Use.

3. Niessink, F. (2002) Software Requirements: Functional \& Non-functional Software Requirements. www.cs.uu.nl/docs/vakken/swa/ Slides/SA-2-Requirements.pdf

4. Ramler, R., Weippl, E., Winterer, M., Shwinger, W., Altmann, J. (2002). A Quality-Driven Approach to Web Testing. Iberoamerican Conference on Web Engineering, ICWE'02. Argentina. September. Vol. 1. pp. 81-95. 